\title{
RACISMO ESTRUTURAL E A VIOLÊNCIA CONTRA A JUVENTUDE NEGRA NO BRASIL
}

Maciana de Freitas e Souza

Pós-graduada em Saúde Pública com Ênfase em Saúde da Família pela instituição Faculdade Vale do Jaguaribe. Bacharela em Serviço Social pela Universidade do Estado do Rio Grande do Norte (UERN).

Francisco Vieira de Souza Junior

Graduando em Direito pelo Centro Universitário Facex. Licenciado em Ciências Sociais pela Universidade do Estado do Rio Grande do Norte (UERN). Bacharel em Administração pela Universidade Potiguar.

\section{RESUMO}

Este estudo propõe uma reflexão sobre o racismo estrutural e a violência contra a juventude negra no Brasil. Para tanto, além de proceder à revisão da literatura, esta pesquisa ancora-se nos dados organizados pelo Fórum Brasileiro de Segurança Pública. Diante disso, nota-se a atuação do Estado, tanto na manutenção do racismo, como na efetivação dos mecanismos de controle social.

Palavras-chave: Racismo estrutural. Violência. Juventude negra. Brasil.

"Somente se conseguirmos pensar de modo diverso a relação entre potência e ato, e, aliás, além dela, será possível conceber um poder constituinte inteiramente livre do bando soberano".

(Giorgio Agamben)

\section{INTRODUÇÃO}

Compreendendo as desigualdades históricas que permeiam o cotidiano da população negra, é possível assinalar as imensas limitações que os povos negros vivenciam ainda hoje no Brasil. Com a escravatura, que vitimou os negros africanos, a princípio, e os negros nascidos em solo brasileiro, posteriormente, as mudanças promovidas pela Lei Áurea, em maio de 1888, foram insuficientes para esse segmento do ponto de vista social e político. 
Assim, o processo de inferiorização das pessoas negras se manteve presente, tendo como objetivo a manutenção do poder dos grupos dominantes.

Em uma perspectiva histórica recente, o processo de redemocratização política, contribuiu para a criação de ações afirmativas na dinâmica societária, com vistas à formulação de políticas públicas e à garantia dos direitos da população negra. No entanto, esse período é marcado pelo contexto neoliberal, com mudanças estruturais no processo de produção capitalista, disso decorre o desenvolvimento da matriz econômica em detrimento dos direitos constitucionais.

Com essas indicações, o objetivo deste texto é analisar o aumento da violência sobre os jovens negros no Brasil a partir do projeto neoliberal ${ }^{1}$. Esta análise se desenvolve por meio de uma pesquisa bibliográfica e documental, a partir do estudo de teóricos que versam sobre a questão do racismo estrutural e dos direitos humanos, além de dados organizados pelo Fórum Brasileiro de Segurança Pública. Portanto, trata-se de uma pesquisa de natureza fundamentalmente qualitativa, referenciada no materialismo histórico dialético enquanto instrumento de apreensão da realidade social em movimento.

Na primeira parte, serão traçados alguns elementos a respeito do racismo estrutural. No segundo item, será apresentada uma abordagem mais geral das legislações criadas pelo Estado e das medidas em curso no contexto do neoliberalismo. E, na terceira parte, será evidenciada uma síntese do aumento da violência contra a juventude negra na sociedade brasileira à luz do debate acerca do Estado de exceção em Giorgio Agamben. Nas considerações finais, serão colocados alguns apontamentos sobre a relevância desse tema na atualidade.

Nesse sentido, entende-se que esse estudo é necessário para que se possa pensar a temática da violência contra a juventude negra no Brasil e as possíveis políticas de enfrentamento da mesma. Desse modo, a violência, enquanto expressão da questão social, apresenta-se importante a criação de políticas públicas que possam contribuir para transformar esta realidade.

\section{ALGUMAS CONSIDERAÇÕES SOBRE O RACISMO ESTRUTURAL}

\footnotetext{
${ }^{1} \mathrm{O}$ neoliberalismo é em primeiro lugar uma teoria das práticas político econômicas que propõe que o bem-estar humano pode ser melhor promovido liberando-se as liberdades e capacidades empreendedoras individuais no âmbito de uma estrutura institucional caracterizada por sólidos direitos a propriedade privada, livres mercados e livre comércio. O papel do Estado é criar e preservar uma estrutura institucional apropriada a essas práticas. (HARVEY,2008, p. 12)
} 
O processo de colonização portuguesa deu-se, incialmente, com a exploração dos índios. Posteriormente, a escravidão dos negros foi instituída como forma de trabalho na Colônia. Neste modo de produção, violências diversas eram praticadas para a manutenção da ordem vigente. Nas palavras de Concolato, "os acontecimentos históricos que desenharam a formação social e capitalista do Brasil, são responsáveis pela polarização social e econômica entre grupos distintos" (CONCOLATO, 2014, p.11).

Na mesma perspectiva, ao tratar do Período Colonial, Florestan Fernandes (2008) indica que a violência estava ligada à estrutura social, mantendo as disparidades entre brancos e negros, e que, mesmo com o movimento abolicionista, tais mudanças não chegaram à população negra, fazendo com que esses sujeitos continuassem subordinados. Nas palavras de Fernandes:

\begin{abstract}
A desagregação do regime escravocrata e senhorial se operou, no Brasil, sem que se cercasse a destituição dos antigos agentes de trabalho escravo de assistência e garantias que os protegessem na transição para o sistema de trabalho livre. Os senhores foram eximidos da responsabilidade pela manutenção e segurança dos libertos, sem que o Estado, a Igreja ou qualquer outra instituição assumisse encargos especiais, que tivessem por objeto prepará-los para o novo regime de organização da vida e do trabalho. O liberto se viu convertido, sumária e abruptamente, em senhor de si mesmo, tornando-se responsável por sua pessoa e por seus dependentes, embora não dispusesse de meios materiais (...) para realizar essa proeza nos quadros de uma economia competitiva. Essas facetas da situação humana do antigo agente do trabalho escravo imprimiram à Abolição o caráter de uma espoliação extrema e cruel. Ela se converteu como asseverava Rui Barbosa 10 anos depois, numa ironia atroz. (FERNANDES, 2008, p. 29)
\end{abstract}

Após a abolição da escravatura, algumas mudanças importantes emergiram na dinâmica societária. Contudo, a forma de domínio econômico e político, exercido pelos grupos dominantes, se manteve na dinâmica social. Com isso, as pessoas negras continuaram expostas à violência e à inferiorização. Nas palavras de Concolato (2014), o Estado legitimou o racismo e, assim, o povo negro estava desprovido de qualquer direito.

\footnotetext{
Por longos anos o negro foi submetido às mais duras formas de servidão e subserviência, escrevendo a história desse país, o último país da América Latina a decretar a Abolição da Escravidão. E, mesmo após a Lei Áurea (1888), a situação do negro não se alterou, visto que a este foi negado o direito à terra, ao emprego e ao ensino, uma vez que o Estado não ofereceu nenhuma forma de garantia a esses sujeitos recém libertos (CONCOLATO, 2014, p. 12)
}

Na mesma perspectiva, o sociólogo peruano Quijano, a partir de uma visão descolonial, afirma que "a escravidão foi estabelecida e organizada como mercadoria para produzir mercadorias para o mercado mundial e, desse modo, para servir aos propósitos e 
necessidades do capitalismo" (QUIJANO, 2005, p.126). O referido autor considera que esse processo histórico deixou inúmeros desafios para a população negra, visto que esse contexto legitimou uma estrutura elitista e excludente.

Dessa maneira, a escravidão dos negros trazidos da África contribuiu para a perpetuação das relações de poder a favor dos grupos dominantes. Nesse contexto, “[...] o controle do capital e do mercado eram e são os que decidem os fins, os meios e os limites do processo. O mercado é o mínimo, mas também o limite da possível igualdade social entre as pessoas" (QUIJANO, 2005, p.125).

Nesse diapasão, ao analisar a formação do Estado brasileiro, Florestan Fernandes mostra que, para defender os interesses das classes dominantes, o racismo se mantém como mecanismo de produção e reprodução social da lógica capitalista. Assim, dá-se "uma cissura entre o presente e o passado (coexistentes e interdependentes como dimensões da vida societária)" (FERNANDES, 2005, p. 56). Nesse contexto, Fernandes (2005) entende que o racismo deve ser visto não somente como um elemento intersubjetivo, mas enquanto uma questão estrutural presente no tecido social da realidade brasileira, mantendo, na prática, uma série de desigualdades que segue até os dias atuais.

No caso brasileiro, pode-se notar que, mesmo após a Constituição Federal de 1988, denominada "Constituição Cidadã", o país ainda convive com índices crescentes de violência contra a juventude negra. Nesse sentido, é possível perceber que são muitos os desafios a serem enfrentados para que seja garantida a proteção necessária para esse grupo. Desse modo, a organização do Estado reproduz, em termos político-econômicos, e, principalmente, em termos ideológico-culturais, a lógica colonialista, contribuindo, assim, para manutenção das desigualdades e dos fatores de perpetração da violência. Nas palavras de Concolato:

\footnotetext{
O racismo que aqui se firmava foi fortalecido com o projeto de nação que previa tornar o Brasil um país majoritariamente branco, submetendo os negros aos lugares mais degradantes, aos piores empregos e as mais precárias condições de moradia, condenado assim que foi à raça inferior (CONCOLATO, 2014, p. 13).
}

Essa visão, exposta por Concolato (2014), mostra que, apesar das conquistas que asseguram formalmente certos direitos políticos e sociais, as práticas políticas e econômicas em curso dificultam a existência de um Estado Democrático de Direito, visto que tais práticas produzem e ampliam as desigualdades. Na mesma direção, segundo Silvio de Almeida, “[...] a manutenção deste poder adquirido depende da capacidade do grupo dominante de 
institucionalizar seus interesses, impondo a toda a sociedade regras, padrões de conduta e modos de racionalidade" (ALMEIDA, 2018, p. 31).

Visto isso, tem-se que esse contexto de desigualdades coloca em xeque o mito da democracia racial $^{2}$, uma vez que, na perspectiva de Silvio de Almeida (2018), o racismo incide na dificuldade de obter proteção jurídica e, com base nisso, são ampliadas as medidas de controle por parte do Estado sob os indivíduos vitimados por ele. As ações para o exercício e a garantia dos direitos fundamentais são cada vez mais difíceis, dado o avanço dos setores conservadores, pois "em um país desigual como o Brasil, a meritocracia avaliza a desigualdade, a miséria e a violência, pois dificulta a tomada de posições políticas efetivas contra a discriminação racial, especialmente por parte do poder estatal” (ALMEIDA, 2018, p.63).

Dessa forma, o racismo deve ser compreendido como um fenômeno social constituído historicamente na realidade brasileira, e que, apesar dos avanços nos últimos anos, as relações sociais e o quadro jurídico-institucional presente acentuam os elementos que sustentam as desigualdades. Destarte, mesmo com o sentido jurídico de igualdade étnicoracial, se mantém os desafios na realidade para garantir os direitos sociais e democráticos.

\section{AVANÇOS E DESAFIOS NA DIREÇÃO DA JUSTIÇA}

Dentre as garantias fundamentais presentes no ordenamento jurídico, pode-se citar o art. $3^{\circ}$, inciso IV, da Constituição Federal de 1988, que estabelece como objetivo o Estado brasileiro promover o bem de todos, sem preconceitos de origem, raça, sexo, cor, idade e quaisquer outras formas de discriminação, além de determinar a garantia dos direitos sociais por meio de políticas e ações. Quanto ao enfretamento do racismo, o art. $5^{\circ}$ institui que:

Art. $5^{\circ}-$ Todos são iguais perante a lei, sem distinção de qualquer natureza, garantindo-se aos brasileiros e aos estrangeiros residentes no país a inviolabilidade do direito à vida, a liberdade, a igualdade, a segurança e a prosperidade [...].

- XLI A lei punirá a qualquer discriminação atentatória dos direitos e liberdades fundamentais. (BRASIL, 1988)

\footnotetext{
2 “O fato de parte expressiva da sociedade considerar ofensas raciais como 'piadas', como parte de um suposto espírito irreverente que grassa na cultura popular em virtude da democracia racial, é o tipo de argumento necessário para que o judiciário e o sistema de justiça em geral resista em reconhecer casos de racismo, e que se considerem racionalmente neutros" (ALMEIDA,2018, p. 59).
} 
Constata-se, desse modo, mudanças normativas realizadas pelo Estado com vistas à superação do racismo estrutural. Desta forma, opta-se pela imposição de uma pena inafiançável e imprescritível para o crime de racismo. Em conformidade com a Constituição, foi sancionado, pelo presidente Luiz Inácio Lula da Silva, o Estatuto da Igualdade Racial Lei $\mathrm{n}^{\circ} 12.288 / 2010$, tendo como principal objetivo garantir, à população negra, a defesa dos seus direitos e oportunidades, além do combate à discriminação. Pelo Estatuto da Igualdade Racial (BRASIL, 2010), a discriminação racial ou étnico-racial define-se como:

[...] é considerado toda distinção, exclusão, restrição ou preferência baseada em raça, cor, descendência ou origem nacional ou étnica que tenha por objeto anular ou restringir o reconhecimento, gozo ou exercício, em igualdade de condições, de direitos humanos e liberdades fundamentais nos campos político, econômico, social, cultural ou em qualquer outro campo da vida pública ou privada (BRASIL, 2010).

Hoje, temos no Brasil uma legislação ampliada no campo dos direitos sociais. Porém, ainda se tem muito o que avançar. Como se pode observar, após a Constituição Federal de 1988, os direitos sociais devem ser garantidos pelo Estado brasileiro a todos os cidadãos. Contudo, com o projeto neoliberal, presente na sociedade brasileira a partir da década de 1990, tem-se o crescimento da pauperização, do desemprego, assim como retrocessos no campo das liberdades públicas. Desse modo, pode-se notar um aumento expressivo das desigualdades sociais, tornando claro que ainda há um longo caminho a ser percorrido para a consolidação dessas políticas.

Em um quadro geral, as respostas às expressões da questão social no Brasil têm se dado por medidas de controle social e de repressão do Estado sob as minorias étnicas. Nesse sentido, concorda-se com o filosofo italiano Giorgio Agamben no tocante ao fato de que "o Estado moderno não faz mais, portanto, do que reconduzir à luz o vínculo secreto que une a poder à vida nua" (AGAMBEN, 2007, p. 14).

$\mathrm{Na}$ mesma perspectiva, Rubens Casara (2017), de forma crítica, demonstra os retrocessos em torno dos direitos sociais e a existência de um "Estado de Exceção" no Brasil contemporâneo. Para Casara (2017), está nítido que não se trata de uma simples mudança na dinâmica social e no ordenamento jurídico, mas de suprimir valores essenciais ao Estado democrático. Casara (2017, p. 21-22) conclui que:

O que há de novo na atual quadra histórica, e que sinaliza a superação do Estado Democrático de Direito, não é a violação dos limites ao exercício do poder, mas o desaparecimento de qualquer pretensão de fazer valer estes limites. Isso equivale a dizer que não existe mais uma preocupação democrática, ou melhor, que os valores do Estado Democrático de Direito não produzem mais o efeito de limitar o exercício 
do poder em concreto. Em uma primeira aproximação, pode-se afirmar que na pósdemocracia desaparecem, mais do que a fachada democrática do Estado, os valores democráticos.

Nesse sentido, é interessante notar que, a partir da crise estrutural do capital, é possível notar alterações na lógica econômica e política de diversos países, com repercussões na organização do trabalho e na materialização das políticas sociais. Assim, de acordo com Batista (2013), torna-se perceptível a presença de uma cultura de autoritarismo e de um Estado voltado ao controle social sobre os segmentos sociais mais vulneráveis.

\begin{abstract}
Na transição da ditadura para a "democracia" (1978-1988), com o deslocamento do inimigo interno para o criminoso comum, e com o auxílio luxuoso da mídia, permitiu-se que se mantivesse intacta a estrutura de controle social, com mais e mais investimentos na "luta contra o crime". E, o que é pior, com as campanhas maciças de pânico social, permitiu-se um avanço sem precedentes na internalização do autoritarismo. Podemos afirmar sem medo de errar, que a ideologia do extermínio é hoje muito mais massiva e introjetada do que nos anos imediatamente posteriores ao fim da ditadura. (BATISTA, 2013, p. 134)
\end{abstract}

A dinâmica social em curso se traduz em ações regressivas nas condições de vida dos trabalhadores, tanto através do processo de austeridade dos governos neoliberais, como por meio da destituição dos direitos humanos, das liberdades democráticas e da justiça social. Desse modo, fica nítido que o Estado brasileiro não tem priorizado medidas sérias que possam considerar a origem das questões sociais. Nessa perspectiva, emergem medidas de populismo penal, que reforçam as violações de direitos, tendo como foco, principalmente, a juventude negra. Para Casara (2017, p. 127):

Hoje, percebe-se claramente, que o Sistema de Justiça Criminal se tornou o lócus privilegiado da luta política. Uma luta em que o Estado Democrático de Direito foi sacrificado. Não há como pensar o fracasso do projeto democrático de Estado sem atentar para o papel do Poder Judiciário na emergência do Estado Pós-Democrático.

A partir desse cenário, é notório que a atuação das agências estatais é desenvolvida para servir aos interesses das classes dominantes, sem considerar os princípios democráticos e a realidade social, não sendo capazes de superar as causas da violência, caminhando no sentido contrário das garantias fundamentais. Casara (2017, p. 39-40) demonstra que:

O mercado tornou-se o eixo orientador de todas as ações, uma vez que foi elevado a núcleo fundamental responsável por preservar a liberdade econômica e política. Os bens, as pessoas, os princípios e as regras passaram a ser valorizadas apenas na condição de mercadorias, isto é, passaram a receber o tratamento conferido às mercadorias a partir de seu valor de uso e de troca. Deu-se a máxima desumanização 
inerente à lógica do capital, que se fundamenta na competição, no individualismo e na busca do lucro sem limites.

Destarte, é possível perceber que, nas democracias neoliberais, o Estado está a serviço dos interesses dos grupos dominantes e do capital, mantendo uma democracia restrita e uma ordem autocrática que institui a violência estatal, com o fortalecimento de discursos e práticas autoritárias contra os segmentos vulneráveis. Agamben (2007) pontua que estes elementos se configuram na esfera política com a suspensão dos direitos dos cidadãos:

[...] as democracias parlamentares puderam virar Estados totalitários, e os Estados totalitários converter-se quase sem solução de continuidade em democracias parlamentares. Em ambos os casos, estas reviravoltas produziam-se num contexto em que a política já havia se transformado, fazia tempo, em biopolítica, e no qual a aposta em jogo consistia então apenas em determinar qual forma de organização se revelaria mais eficaz para assegurar o cuidado, o controle e o usufruto da vida nua. (AGAMBEN, 2007, p. 127-128)

Nesse sentido, no próximo item, a partir da análise de dados levantados pelo Fórum Brasileiro de Segurança Pública, será apresentada uma reflexão crítica sobre o aumento da violência contra a juventude negra no Brasil e acerca do Estado de Exceção, enquanto elemento central da política contemporânea, conforme analisa Agamben.

\section{O AUMENTO DA VIOLÊNCIA CONTRA A JUVENTUDE NEGRA}

No estudo intitulado "Democracia racial e homicídios de jovens negros na cidade partida", Cerqueira e Coelho (2017) identificaram que a violência contra a juventude negra tem aumentado significativamente no país e que, mesmo com os marcos legais instituídos, notam-se desafios para a efetividade dessas políticas no plano concreto.

Desde princípios dos anos 1980, o país vem assistindo a uma escalada de homicídios da juventude negra. A taxa de homicídio no Brasil para homens negros com 21 anos de idade alcançou quase 180 por cem mil habitantes em 2010. Os indicadores de letalidade violenta para jovens e negros nas Unidades Federativas alcançam cifras ainda mais abissais, bem como a diferença de letalidade entre esses e os não negros. Se, no Brasil, para cada indivíduo não negro assassinado, 2,4 afrodescendentes eram mortos (já considerando proporcionalmente o tamanho das populações por raça-cor), em estados como Alagoas para cada não negro assassinado 17 negros sofriam homicídio, em 2010 (CERQUEIRA; COELHO, 2017, p. 30).

O Atlas da Violência (2019), produzido pelo Instituto de Pesquisa Econômica Aplicada - (IPEA) e pelo Fórum Brasileiro de Segurança Pública (FBSP), apresenta os 
indicadores sobre o aumento da violência no país e atualiza tais dados. Com relação ao quadro geral, o estudo indica altas taxas de vitimização para esse grupo.

Em 2017, 75,5\% das vítimas de homicídios foram indivíduos negros (definidos aqui como a soma de indivíduos pretos ou pardos, segundo a classificação do IBGE, utilizada também pelo SIM), sendo que a taxa de homicídios por 100 mil negros foi de 43,1, ao passo que a taxa de não negros (brancos, amarelos e indígenas) foi de 16,0 . Ou seja, proporcionalmente às respectivas populações, para cada indivíduo não negro que sofreu homicídio em 2017, aproximadamente, 2,7 negros foram mortos. (INSTITUTO DE PESQUISA ECONOMICA APLICADA, 2019, p. 49).

O documento citado também evidencia que, no Brasil, a violência letal tem como principais vítimas os homens jovens: "do total de óbitos de homens entre 15 a 19 anos são ocasionados por homicídio" (INSTITUTO DE PESQUISA ECONOMICA APLICADA, 2019, p. 06). Ao lado desses dados, que comprovam o processo de expansão da violência estatal, “[...] o país passa pela maior transição demográfica de sua história, rumo ao envelhecimento, o que impõe maior gravidade ao fenômeno" (INSTITUTO DE PESQUISA ECONOMICA APLICADA, 2019, p. 25).

Percebe-se, ainda, de acordo com a pesquisa supracitada, que os jovens negros possuem maiores chances de serem vítimas de ações violentas, refletindo a negação histórica dos direitos desse grupo e "a continuidade do processo de aprofundamento da desigualdade racial nos indicadores de violência letal no Brasil, já apontado em outras edições." (INSTITUTO DE PESQUISA ECONOMICA APLICADA, 2019, p. 51).

A partir desse cenário, é possível entender a dificuldade de acesso aos equipamentos sociais por parte dos jovens negros, além da ideia de que o poder penal sempre incide com mais violência sobre esse segmento, o que confirma o pensamento político de Giorgio Agamben (2004) a respeito do Estado de Exceção.

Para o mencionado filósofo italiano, o Estado de Exceção se constitui com a suspensão da ordem jurídica, e que, nesse caminhar, é possível notar a eliminação física de “inimigos públicos" criados pelo Estado, aqueles que estão à margem da sociedade. Nas palavras de Giorgio Agamben (2004, p. 13):

O totalitarismo moderno pode ser definido, nesse sentido, como a instauração, por meio do estado de exceção, de uma guerra civil legal que permite a eliminação física não só dos adversários políticos, mas também de categorias inteiras de cidadãos que, por qualquer razão, pareçam não integrar o sistema político. Desde então, a criação voluntária de um estado de exceção permanente (ainda que eventualmente não declarado no sentido técnico) tornou-se uma das práticas essenciais dos Estados contemporâneos, inclusive dos chamados democráticos. 
Ao analisar os dados e as estatísticas sobre a situação dos jovens negros na conjuntura brasileira, pode-se inferir que o racismo não só dificulta o usufruto dos direitos, como também, devido a estereótipos, faz aumentar a tendência de a juventude negra sofrer maior coerção por parte do sistema de justiça criminal vigente na sociedade. Desse modo, Giorgio Agamben (2004) indica que:

\begin{abstract}
O estado de exceção é um espaço anômico onde o que está em jogo é uma força de lei sem lei [...]. Tal força de lei, em que potência e ato estão separados de modo radical, é certamente algo como elemento místico, ou melhor, uma fictio por meio da qual o direito busca se atribuir sua própria anomia. Como se pode pensar tal elemento 'místico' e de que modo ele age no estado de exceção é o problema que se deve tentar esclarecer (AGAMBEN, 2004, p. 61).
\end{abstract}

Nesse sentido, fica evidente que o aumento da violência, no que se refere à juventude negra, diz respeito à falta de uma política de segurança pública eficaz, conduzida pelo poder público brasileiro, no que diz respeito ao seu dever de prevenção das mortes violentas. No plano real, as ações empreendidas pelo Estado em nome da "segurança" revelam outras violações de direitos.

Pode-se inferir, desse modo, que as ações em curso pelas agências estatais não têm garantido resultados eficazes, e que os dados apresentados evidenciam um aumento da letalidade da juventude negra. Assim, nota-se que as políticas em curso foram criadas com vistas a atender interesses específicos da classe dominante, e são ligadas ao "poder soberano", pois "inicialmente apresentadas como medidas ligadas a acontecimentos excepcionais, reservadas a situações limitadas no tempo e no espaço, tornam-se regra" (AGAMBEN, 2004, p. 76). A partir disso, é possível dizer que a juventude negra foi reduzida à condição de homo sacer $^{3}$, enquanto sujeitos vulneráveis aos diversos eventos totalitários.

Desse modo, fica nítido que muitas vezes as ações conduzidas pelo Estado brasileiro, com vistas à segurança e à ordem pública, são realizadas sem considerar os direitos fundamentais, e, assim, legitimam a violência e a arbitrariedade. Na mesma perspectiva, Batista (2013, p. 133) afirma que o Estado de exceção atua como "configurador e dirigido aos setores pobres e aos dissidentes, com o máximo de arbitrariedade seletiva. O marco deste sistema de controle social tem sido o genocídio".

No caso do Brasil, as políticas públicas para a população negra ainda são incipientes e, desse modo, o racismo se constitui como elemento central que dificulta o acesso à cidadania. Destarte, na política contemporânea, se constituem muitos desafios para que

\footnotetext{
${ }^{3}$ Homo sacer (Homem sacro), para Agamben, é "aquele que o povo julgou por um delito; e não é lícito sacrificálo, mas quem o mata não será condenado por homicídio” (AGAMBEN, 2007, p. 196).
} 
diversas garantias sociais sejam cumpridas na realidade. A partir disso, nota-se que há um Estado de Exceção permanente, tanto no que se refere ao aumento das violações de direitos, quanto ao crescimento da letalidade da juventude negra.

Portanto, com base nos dados apresentados pelo Fórum Brasileiro de Segurança Pública, pode-se notar que o país vivencia índices crescentes de violência contra a população negra e que os direitos fundamentais são deixados em segundo plano, em prol de medidas de vigilância. Nesse contexto, é essencial que sejam criadas políticas eficazes, inclusivas e garantidoras de direitos para esses jovens em situação de vulnerabilidade social em detrimento do controle social punitivo.

\section{CONCLUSÃO}

Como visto, no Período Colonial, houve o processo de inferiorização dos povos negros, a partir da escravidão, e o capitalismo que emerge dessas condições contribuiu para a manutenção dessas relações de poder. Com isso, diversas expressões de violência podem ser observadas e o racismo se apresenta ainda mais significativo na estrutura social.

A interlocução entre as referências indica que, mesmo com as mudanças sociais, a partir da transição democrática, é possível notar fragilidades nas políticas criadas com vistas à igualdade racial. A atuação do Estado hoje está voltada para ampliação do capital e se constitui a favor dos grupos dominantes, visto que são muitos os desafios para que a população negra tenha acesso aos direitos sociais.

A partir de todas as análises apresentadas, pode-se, então, considerar que o racismo se constitui como elemento importante no processo de reprodução da lógica capitalista, e que, no Estado brasileiro, há um aumento crescente de letalidade da juventude negra, o que reforça a ideia de que as tarefas democráticas não estão sendo conduzidas pelo Estado.

É possível notar que os elementos da obra de Giorgio Agamben seguem sendo atuais na realidade brasileira, uma vez que o ordenamento jurídico é suspenso, e, assim, a juventude negra não é reconhecida enquanto "sujeito de direitos". Havendo, dessa forma, um aumento expressivo dos homicídios, no que diz respeito a jovens negros de 15 a 29 anos com baixa escolaridade.

Desse modo, no Brasil, a população negra está exposta a diversas formas de violência e o racismo se constitui como elemento fundante da exclusão desse segmento, do mercado de trabalho e do contexto de cidadania. Observa-se, também, que, a partir do 
neoliberalismo, essas condições de vulnerabilidade social são ampliadas, em virtude da dificuldade de implantação das políticas públicas.

É válido reconhecer que as legislações criadas estabelecem a importância de enfrentamento ao racismo estrutural. Contudo, segue prevalecendo, na sociedade brasileira, pelas agências estatais, a reprodução dessas desigualdades. Dessa forma, nesse contexto, temse o fortalecimento de um Estado penal em detrimento de um Estado de Direito, em prol das garantias sociais.

Portanto, a partir das bases teóricas estudadas, é possível perceber que se constituem desafios para a efetivação dos direitos humanos e sociais, previstos no plano formal, e que a juventude negra brasileira vivencia uma série de desigualdades e violações de direitos, provando que o racismo continua presente na sociedade brasileira, como também mostra a existência de espaços de exceção.

\section{REFERÊNCIAS}

AGAMBEN, Giorgio. Homo Sacer: o poder soberano e a vida nua I. Tradução de Henrique Burigo. Belo Horizonte: Editora UFMG, 2007.

Giorgio. Estado de exceção. Tradução de Iraci D. Poleti. São Paulo: Editora Boitempo, 2004

ALMEIDA, Silvio Luiz de. O que é racismo estrutural? Belo Horizonte: Letramento, 2018.

BATISTA, Vera Malaguti. Difíceis ganhos fáceis: drogas e juventude pobre no Rio de Janeiro. 1. reimp. Rio de Janeiro: Revan, 2003.

BRASIL. Congresso Nacional. Estatuto da Igualdade Racial: Lei ${ }^{\circ} 12.288$, de 20 de julho de 2010. Brasília: Câmara dos Deputados, 2010.

Governo Federal. Constituição da República Federativa do Brasil (1988).

Brasília: Senado Federal, 1988. 
CERQUEIRA, Daniel; COELHO, Danilo Santa Cruz. Democracia racial e homicídios de jovens negros na cidade partida. Brasília: IPEA, 2017. Disponível em:

<http://www.ipea.gov.br/portal/images/stories/PDFs/TDs/td_2267.pdf>. Acesso em: 14 set. 2019.

CONCOLATO, Bianca Machado. Do escravismo às políticas de ações afirmativas: o negro cotista na Universidade Federal de Juiz de Fora. 2014. Dissertação (Mestrado em Serviço Social) - Programa de Pós-Graduação em Serviço Social - PPGSS, Universidade Federal de Juiz de Fora. Disponível em:

<https://repositorio.ufjf.br/jspui/bitstream/ufjf/617/1/biancamachadoconcolatovieira.pdf $>$. Acesso em: 14 set. 2019.

FERNANDES, Florestan. A integração do negro na sociedade de classes: o legado da "raça branca". 5a . ed. São Paulo: Globo, 2008. v. 1.

A revolução burguesa no Brasil: ensaio de interpretação sociológica. 5. ed. São Paulo: Globo, 2005.

HARVEY, David. O neoliberalismo: história e implicações. São Paulo: Ed. Loyola, 2008.

INSTITUTO DE PESQUISA ECONOMICA APLICADA. Atlas da Violência 2019. Rio de Janeiro, 2019.

QUIJANO, Aníbal. Colonialidade do poder, eurocentrismo e América Latina. In: LANDER, Edgardo et. al. (Ed.). A colonialidade do saber: eurocentrismo e ciências sociais: perspectivas latino-americanas. CLACSO, Ciências Sociais, 2005.

STRUCTURAL RACISM AND VIOLENCE AGAINST BLACK YOUTH IN BRAZIL

\begin{abstract}
This study proposes a reflection on structural racism and violence against black youth in Brazil. Therefore, in addition to reviewing the literature, this research is based on data organized by the Brazilian
\end{abstract}


| Revista Transgressões: ciências criminais em debate, v. 7, dezembro de 2019

Public Security Forum. In view of this, the State acts both in the maintenance of racism and in the implementation of social control mechanisms.

Keywords: Structural racism. Violence. Black youth. Brazil. 